J. Dairy Sci. 95:3579-3592

http://dx.doi.org/10.3168/jds.2011-5223

(C) American Dairy Science Association ${ }^{\circledR}, 2012$.

\title{
Structural changes of bovine milk fat globules during in vitro digestion
}

\author{
S. Gallier, ${ }^{1}$ A. Ye, and H. Singh \\ Riddet Institute, Massey University, Private Bag 11 222, Palmerston North 4442, New Zealand
}

\begin{abstract}
An in vitro digestion model that simulated gastric and intestinal fasting conditions was used to monitor the physical, chemical, and structural changes of fat globules from raw bovine milk. During in vitro gastric digestion, the fat globules were stable under lowacidic conditions. Some peptides and $\beta$-lactoglobulin were resistant to proteolysis by pepsin. Phospholipids, proteins, and peptides stabilized the globules in the stomach model. During in vitro intestinal digestion, most of the $\beta$-lactoglobulin and residual peptides were hydrolyzed by trypsin and chymotrypsin, and the lipolytic products, released from the hydrolysis of the triglyceride core of the globules, led to destabilization and coalescence of the globules. By accumulating at the surface of the fat globules, the lipolytic products formed a lamellar phase and their solubilization by bile salts resulted in the formation of disk-shaped micelles. This study brings new interesting insights on the digestion of bovine milk.
\end{abstract}

Key words: in vitro digestion, milk fat globule membrane, confocal microscopy

\section{INTRODUCTION}

Milk is an oil-in-water emulsion. The structure of the bovine milk fat globule and its membrane in its native state was a subject of great interest in the 1970s (Anderson and Brooker, 1975; Patton and Keenan, 1975), with a recent renewal of interest encouraged by new techniques of investigation (Gallier et al., 2010; Lopez et al., 2010; Vanderghem et al., 2011). Milk fat globules are kept in suspension in the milk serum phase because of the presence of a trilayer of phospholipids, which embeds proteins, glycoproteins, and cholesterol. This unique milk fat globule membrane (MFGM) presents a particular lateral phospholipid distribution with the coexistence of a liquid-ordered phase, rich in sphingomyelin and cholesterol, and a liquid-disordered phase, rich in unsaturated phospholipids (Gallier et al., 2010).

Received December 5, 2011

Accepted March 10, 2012.

${ }^{1}$ Corresponding author: S.Gallier@massey.ac.nz
This phase coexistence may play a role in the digestion of milk fat globules, as shown in a dipalmitoylphosphatidylcholine (DPPC) condensed monolayer system after the addition of bile salts; the pancreatic lipase-colipase complex adsorbs only onto mixed bile salt-DPPC regions and not at all onto the DPPC condensed phase (Maldonado-Valderrama et al., 2011). Therefore, the presence of sphingomyelin- and cholesterol-rich liquidordered domains may protect the milk fat globule from lipolysis.

Milk fat globule membrane proteins may also play a role in the digestion of milk fat globules. Many of the MFGM proteins, including butyrophilin, which accounts for $40 \%$ of the MFGM proteins, are glycosylated (Singh, 2006). The degree of glycosylation of the membrane proteins has a protective role against hydrolysis by pepsin and, therefore, the glycoproteins maintain their structure and function during the digestion of human milk fat globules (Hamosh et al., 1999). Thus, the glycocalyx, formed by the carbohydrate moieties of glycoproteins and gangliosides and surrounding the bovine milk fat globules, may influence the digestion of the milk fat globule and contribute to the protective role of the milk fat globule (Hamosh et al., 1999). Gallier et al. (2011) showed recently the interaction of $\beta-\mathrm{CN}$ with milk phospholipid monolayers. This model system revealed a possible clustering of liquid-ordered domains at the surface of the bovine milk fat globules that is caused by specific milk protein-phospholipid interactions. Therefore, the slow rate of digestion of MFGM proteins may prevent the loss of integrity of the MFGM during digestion and influence the lipolysis process by preventing gastric and pancreatic lipases from accessing the triglyceride core.

The bovine milk fat globules have a diameter between 0.2 and $15 \mu \mathrm{m}$. A small globule size distribution results in slower gastric emptying (Michalski, 2009). Emulsions with small droplets are digested faster than emulsions with large droplets, as they provide a larger surface area for the binding of enzymes and lipolysis to occur (Singh et al., 2009). Therefore, bovine milk fat globules will be digested at different rates according to their initial size. Milk triglycerides are rich in SFA, short-chain FA (SCFA), and medium-chain FA (MCFA) (Jensen and Newburg, 1995). The sn-3 position on the triglyc- 
eride backbone contains SCFA, the saturated MCFA are located on the sn- 2 and sn- 1 positions, and the saturated long-chain FA (LCFA) are located on the sn-2 position (Jensen and Newburg, 1995). This, again, will affect the rate of lipolysis, as gastric lipase has a preference for the sn-3 position and MCFA (van Aken et al., 2011), whereas pancreatic lipase is $s n-1$ and $s n-3$ specific and is more active on MCFA than on LCFA (Armand, 2007; N'Goma et al., 2012). Short-chain FA and MCFA have a high dispersibility in aqueous media and will, therefore, be solubilized easily into mixed bile salt-phospholipid micelles and further transported into the portal vein and through the liver to finally enter the systemic circulation. In contrast, LCFA tend to accumulate at the oil-water interface, inhibiting the action of lipases until they are precipitated by calcium ions into insoluble soaps. Long-chain FA are further assembled into chylomicrons for their transport through the lymph system to reach the systemic circulation (McClements et al., 2008).

However, following lipolysis in vivo presents technical difficulties such as the use of cannulations. To overcome the cost and physiological variations occurring during in vivo studies, a simple model of in vitro digestion was chosen to monitor, in a reproducible manner, the gastric and intestinal digestion of native bovine milk fat globules. This study extends recent work by our group in which bovine milk fat globules were digested under gastric conditions only with a focus on MFGM proteins (Ye et al., 2011) and intestinal conditions without pregastric digestion (Ye et al., 2010).

\section{MATERIALS AND METHODS}

\section{Samples and Reagents}

Fresh raw bovine milk from pasture-fed (with grass silage) Friesian cows was collected from the Massey University No. 1 Dairy Farm (Palmerston North, New Zealand). If not used the same day, sodium azide [Merck KGaA, Darmstadt, Germany; 0.02\% (wt/vol)] was added and the milk was kept at $4^{\circ} \mathrm{C}$ for a maximum of $2 \mathrm{~d}$. Milk is often kept at $4^{\circ} \mathrm{C}$ before consumption and is slowly warmed up to $37^{\circ} \mathrm{C}$ upon passage through the gastrointestinal tract. However, it has to be kept in mind that cooling of the milk leads to a loss of MFGM phospholipids (Baumrucker and Keenan, 1973), deformation of the MFGM (Lopez, 2011) due to protruding crystals (Michalski et al., 2004), and an increased amount of solid fat which is less digestible than liquid fat (Bonnaire et al., 2008).

Pepsin from porcine gastric mucosa (EC 3.4.23.1; catalog no. P7000; 800 to $2,500 \mathrm{U} / \mathrm{mg}$ of protein), porcine bile extract [B8631; including, as stated by the manufacturer, hyodeoxycholic acid (1 to $5 \%$ ), deoxycholic acid (0.5 to $7 \%$ ), cholic acid (0.5 to $2 \%$ ), glycodeoxycholic acid (10 to 15\%), and taurodeoxycholic acid (3 to 9\%)], and porcine pancreatin (catalog no. P1750; $4 \times$ USP) were purchased from Sigma-Aldrich Corp. (St. Louis, MO). All other chemicals were of analytical grade and were purchased from Sigma-Aldrich Corp. unless specified otherwise.

\section{In Vitro Gastric Digestion}

The in vitro gastric digestion model simulated the fasted state in humans. Raw milk $(20 \mathrm{~mL})$ was mixed with $10 \mathrm{~mL}$ of simulated gastric fluid (SGF) containing $2 \mathrm{~g}$ of $\mathrm{NaCl} / \mathrm{L}$ and $7 \mathrm{~mL}$ of $\mathrm{HCl} / \mathrm{L}$ at $\mathrm{pH} 1.2$ (US Pharmacopeia, 2000). The milk-SGF mixture was acidified to $\mathrm{pH} 1.5$ with $6 \mathrm{M} \mathrm{HCl}$ and was incubated for $10 \mathrm{~min}$ at $37^{\circ} \mathrm{C}$ in a shaking water bath at $95 \mathrm{rpm}$. Pepsin $(3.2$ $\mathrm{mg} / \mathrm{mL}$ of SGF) was then added, and the temperature and agitation were maintained for $2 \mathrm{~h}$. Samples were collected periodically for further characterization.

Only 10 to $30 \%$ of lipids are digested by gastric lipase (Hamosh, 1990). However, when food enters the stomach, only a low concentration of gastric lipase is present and will only gradually increase with increasing gastric secretion, while at the same time, gastric emptying proceeds. Thus, the level of product inhibition of gastric lipase may not be reached in the stomach and gastric lipolysis may partly take place in the small intestine (van Aken, 2010). The gastric model chosen in this study did not include a gastric lipase, as it is difficult to obtain commercially. Thus, we focused on the effect of pepsin on the MFGM during gastric digestion and the lipolysis by pancreatic lipase under intestinal conditions. In addition, the activity of gastric lipase is reduced when phosphatidylethanolamine and sphingomyelin, 2 major MFGM phospholipids, are present at the oil-water interface (Armand, 2008). Moreover, the optimal activity of human gastric lipase occurs at $\mathrm{pH} 5.4$, and it was found that its activity was minimal at $\mathrm{pH} 3$ (Gargouri et al., 1986). The chosen gastric model presents a very low acidic $\mathrm{pH}$ of 1.5 , simulating fasting conditions, which is close to the optimal $\mathrm{pH}$ of pepsin activity of 2 (Boyer, 1971), but well below the optimal $\mathrm{pH}$ of gastric lipase activity. Thus, at this $\mathrm{pH}$, the activity of gastric lipase on bovine milk fat globules can be considered insignificant.

\section{In Vitro Intestinal Digestion and FFA Release}

Simulated intestinal fluid (SIF) was prepared with $6.8 \mathrm{~g}$ of $\mathrm{K}_{2} \mathrm{HPO}_{4} / \mathrm{L}$ and $190 \mathrm{~mL} 0.2 \mathrm{M} \mathrm{NaOH} / \mathrm{L}$ and maintained at pH 7.5 (US Pharmacopeia, 1995). Simulated intestinal fluid also included $150 \mathrm{mM} \mathrm{NaCl}$ to 
simulate in vivo intestinal ionic strength. After $1 \mathrm{~h}$ of gastric digestion of milk as described above, the in vitro intestinal digestion, simulating intestinal fasting conditions, was carried out by mixing the digested bovine milk with SIF (1:1) to a total volume of $30 \mathrm{~mL}$, adjusting the $\mathrm{pH}$ at 7 , and adding bile extract $(5 \mathrm{mg} / \mathrm{mL})$ in a conical flask. The mixture was incubated at $37^{\circ} \mathrm{C}$ in a shaking water bath $(95 \mathrm{rpm})$ for $10 \mathrm{~min}$. Pancreatin $(1.6 \mathrm{mg} / \mathrm{mL})$ was added to the system, the $\mathrm{pH}$ was maintained at 7 with $1 \mathrm{M} \mathrm{NaOH}$, and samples were taken periodically for characterization over $2 \mathrm{~h}$.

Pancreatic lipase activity was measured over $2 \mathrm{~h}$ using a pH-stat titration method (TitraLab 856; Radiometer Analytical, Villeurbanne, France) with $0.05 M$ $\mathrm{NaOH}$ and an endpoint of $\mathrm{pH}$ 7.0. The FFA released by pancreatic lipolysis were back titrated at the end of the $2 \mathrm{~h}$ of intestinal digestion by shifting the $\mathrm{pH}$ from 7 to 9 . A blank titration without any pancreatin was carried out.

\section{Protein Hydrolysis}

The protein composition of digested milk samples under gastric and intestinal conditions was determined by SDS-PAGE. Small aliquots $(50 \mu \mathrm{L}$ under gastric conditions and $100 \mu \mathrm{L}$ under intestinal conditions) of samples were treated with $200 \mu \mathrm{L}$ (under gastric conditions) or $150 \mu \mathrm{L}$ (under intestinal conditions) of tricine sample buffer $[0.2 M$ Tris-HCl buffer $\mathrm{pH}$ 6.8, $40 \%$ glycerol, 2\% SDS, 0.04\% Coomassie Brilliant Blue R-250, and $\beta$-mercaptoethanol (19:1, vol:vol)] and heated at $95^{\circ} \mathrm{C}$ for $5 \mathrm{~min}$. The samples were left to cool to room temperature $\left(21 \pm 1^{\circ} \mathrm{C}\right)$ and centrifuged for $5 \mathrm{~min}$ at $1,000 \times g$, and then $10 \mu \mathrm{L}$ of subnatant was loaded on to a precast Criterion 10 to $20 \%$ gradient tricine gel (Bio-Rad Laboratories Pty., Auckland, New Zealand). The gel was stained for $40 \mathrm{~min}$ with a solution of Coomassie Brilliant Blue R-250 [0.003\% (wt/vol) in 10\% acetic acid (BDH, Poole, UK) and 20\% isopropanol (Merck KGaA, Darmstadt, Germany)]. The gel was destained with a solution of $10 \%$ acetic acid and $10 \%$ isopropanol and scanned using a Molecular Imager Gel Doc XR (Bio-Rad Laboratories Pty.). Precision Plus protein unstained standards (10 to $250 \mathrm{kDa}$ ) and polypeptide SDS-PAGE standards (1.4 to $26.6 \mathrm{kDa}$ ) were obtained from Bio-Rad Laboratories Pty.

\section{Measurement of $\zeta$-Potential}

The $\zeta$-potential of the raw bovine milk fat globules and digested samples was measured by a laser Doppler velocimetry and phase analysis light-scattering technique using a Malvern Zetasizer Nano ZS instrument (Malvern Instruments Ltd., Worcestershire, UK). The raw milk was diluted 100-fold in Milli-Q water (Millipore Corp., Billerica, MA), gastric digested samples were diluted 100 -fold in a $10 \mathrm{~m} M$ citrate buffer $(\mathrm{pH}$ 2.5 ), and intestinal digested samples were diluted 100fold in PBS solution ( $\mathrm{pH} 7.2$ ). The temperature was equilibrated at $25^{\circ} \mathrm{C}$ by a Peltier system. The refractive index of milk fat is 1.456 with an absorbance of 0.001 , and the refractive index of the aqueous phase is 1.33 (Ye et al., 2010). The Smoluchowski approximation was applied to calculate the $\zeta$-potential from the electrophoretic mobility measurement (Michalski et al., 2002). Ten readings from an individual sample were collected and the triplicate measurements were repeated at least on 3 individual digestion experiments.

\section{Particle Size Distribution}

A Malvern MasterSizer MSE (Malvern Instruments Ltd., Worcestershire, UK) was used to determine the average particle size of raw milk fat globules and digested samples. The samples were diluted in water in the measurement cell of the equipment until $15 \%$ obscuration was reached. The Sauter average diameter $\left(\mathbf{d}_{\mathbf{3 2}}\right)$ and the volume mean diameter $\left(\mathbf{d}_{43}\right)$ of the samples were measured, as $d_{43}$ is more sensitive to large particles, whereas $d_{32}$ is more sensitive to small particles (Mun et al., 2007). Mean particle diameters were calculated as the average of duplicate measurements and the measurements were run in triplicate on different milk samples and digested milk samples.

\section{Confocal Laser Scanning Microscopy}

The microstructure of raw bovine milk fat globules and digested milk samples was studied using a confocal laser scanning microscope (Leica DM6000B; Leica Microsystems, Heidelberg, Germany) with a $63-\mathrm{mm}$ oil immersion objective lens. Agarose [50 $\mu \mathrm{L}, 0.5 \%$ (wt/ vol) in deionized water] was used to fix the sample (25 $\mu \mathrm{L})$ on the slide. Nile Red [9-diethylamino-5H-benzo $[\alpha]$ phenoxazine-5-one, $1 \mathrm{mg} / \mathrm{mL}$ in dimethyl sulfoxide, $1: 100$ (vol/vol)] was used to stain the triglycerides, Fast Green FCF [disodium2-[[4-[ethyl-[(3-sulfonatophenyl) methyl]amino]phenyl]-[4-[ethyl-[(3-sulfonatophenyl) methyl] azaniumylidene]cyclohexa-2,5-dien-1-ylidene] methyl]-5-hydroxybenzenesulfonate, $1 \mathrm{mg} / \mathrm{mL}$ in MilliQ water, 1:100 (vol/vol)] was used to stain the proteins, and the Alexa Fluor 488 conjugate of wheat germ agglutinin $[1 \mathrm{mg} / \mathrm{mL}$ in $0.2 \mathrm{M} \mathrm{PBS}(\mathrm{pH} 7.4)$; Invitrogen Corp., Carlsbad, CA; 1:30 (vol/vol)] was used to stain the glycoproteins and glycolipids. The fluorescent head-group-labeled phospholipid analog Lissamine rhodamine B 1,2-dihexadecanoyl-sn-glycero-3-phosphoethanolamine, triethylammonium salt [Rd-DHPE; 


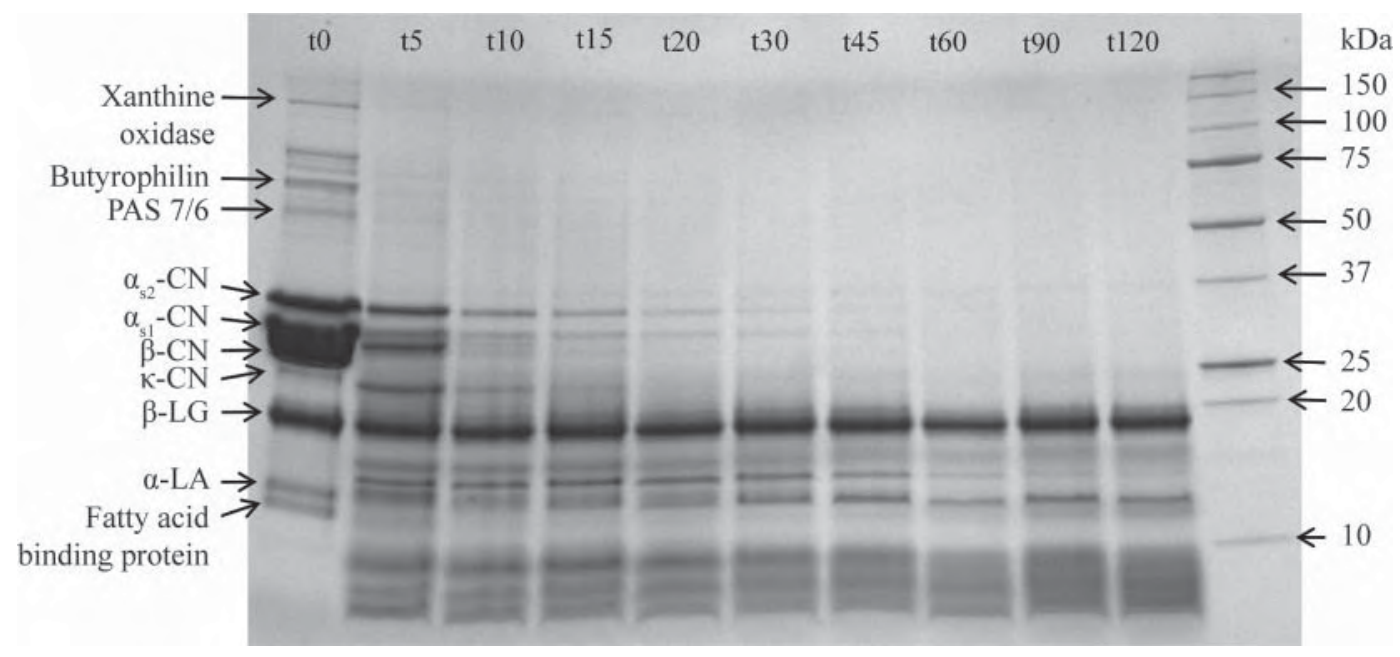

Figure 1. Reducing tricine-SDS-PAGE patterns of bovine milk and digested samples under gastric conditions over 120 min (t0 to t120). PAS = periodic acid-Schiff.

$1 \mathrm{mg} / \mathrm{mL}$ in chloroform; Invitrogen Corp.; 1:60 (vol/ vol)] was used to investigate the lateral distribution of the phospholipids on the surface of the fat globules. For intestinal digested samples, images were acquired using the scan differential interference contrast-polarization (DIC-Pol) mode in combination with fluorescent images. Differential interference contrast microscopy is used to observe motion and structure of a sample, and polarized light microscopy is a contrast-enhancing technique used to observe birefringent samples visible due to their optically anisotropic character (Shribak et al., 2007).

\section{RESULTS AND DISCUSSION}

\section{Gastric Digestion}

Protein Hydrolysis. Figure 1 shows the SDS-PAGE patterns of fresh bovine milk mixed with SGF and the digested milk samples at different times of pepsinolysis under gastric conditions. The main proteins present in the milk-SGF mixture were caseins and whey proteins. Few MFGM proteins were detected (Figure 1). The pepsinolysis of MFGM proteins was recently studied in our laboratory (Ye et al., 2011); butyrophilin was found to be more resistant than xanthine oxidase and periodic acid-Schiff (PAS) 6 and PAS 7 to pepsin. Shimizu et al. (1982) and Hamosh et al. (1999) obtained similar results on the resistance of certain MFGM proteins to hydrolysis by physiological proteases, and associated this resistance with the high degree of glycosylation of some MFGM proteins. $\beta$-Casein and $\kappa$-CN were digested within $10 \mathrm{~min}$, whereas $\alpha_{\mathrm{s} 1}-\mathrm{CN}$ and $\alpha_{\mathrm{s} 2}-\mathrm{CN}$ were still slightly detected in the SDS-PAGE patterns after
45 min of gastric digestion (Figure 1). The hydrolysis of the milk proteins resulted in the formation of peptides of between 15 and $20 \mathrm{kDa}$ and smaller than $10 \mathrm{kDa}$. $\beta$-Lactoglobulin was fairly resistant to pepsinolysis (Figure 1). Sarkar et al. (2009) studied the digestion of $\beta$-LG solutions and $\beta$-LG-stabilized emulsions, and reported that $\beta-\mathrm{LG}$ was resistant to pepsin in its native form but was partially hydrolyzed when adsorbed at the oil droplet surface. In this study, $\beta-\mathrm{LG}$ was not adsorbed at the surface of the milk fat globules, as the milk was not processed. After $2 \mathrm{~h}$ of digestion, $\beta-\mathrm{LG}$ and other milk proteins and peptic products were still detected, suggesting a resistance to further pepsinolysis (Figure 1).

Particle Size Distribution. The particle size distribution and the volume mean and surface mean diameters of bovine milk fat globules during gastric digestion were studied (Figures 2 and 3 ). The native bovine milk fat globules presented a bimodal distribution (Figure 2). The particle size distribution of the milk fat globules remained bimodal during in vitro gastric digestion; however, upon mixing with SGF, the particle size increased dramatically, with a large population of particles between 20 and $160 \mu \mathrm{m}$ in size and a small population of particles of less than $15 \mu \mathrm{m}$ in size. The ratio between the 2 populations decreased over 2 $\mathrm{h}$ of gastric digestion, with the population of smaller particles becoming more numerous than the population of large particles. This translated into decreases in $\mathrm{d}_{43}$ and $\mathrm{d}_{32}$ over the time of digestion (Figure 3 ). Upon mixing bovine milk with SGF, $\mathrm{d}_{43}$ and $\mathrm{d}_{32}$ increased by factors of 25 and 10, respectively. Both particle diameters decreased over the time of digestion, suggesting a breakdown of aggregates as a result of pepsinolysis. 


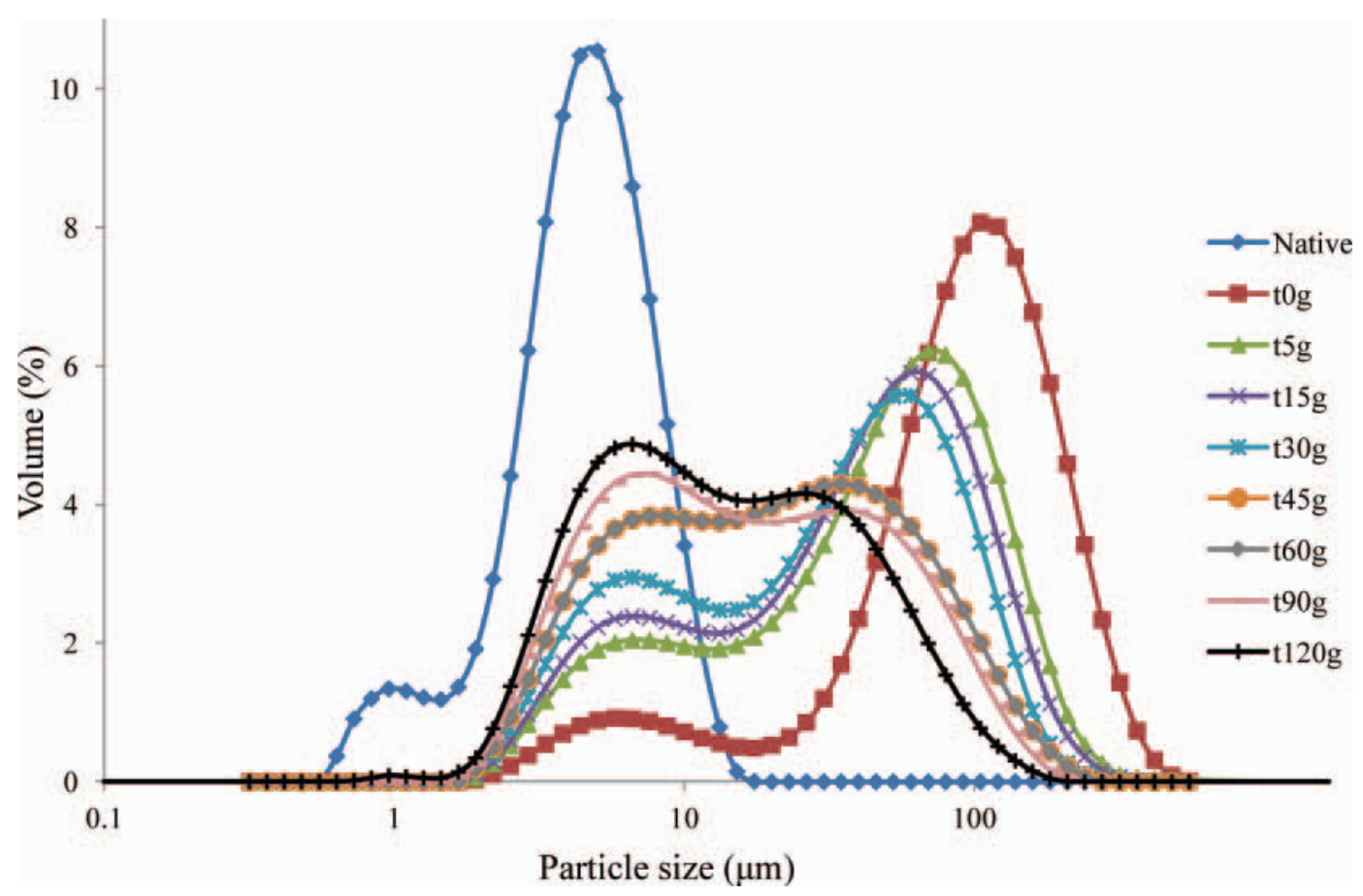

Figure 2. Particle size distribution of bovine milk (native) and digested samples [from 0 (t0g) to 120 (t120g) min of gastric digestion with pepsin]. Color version in the online PDF.

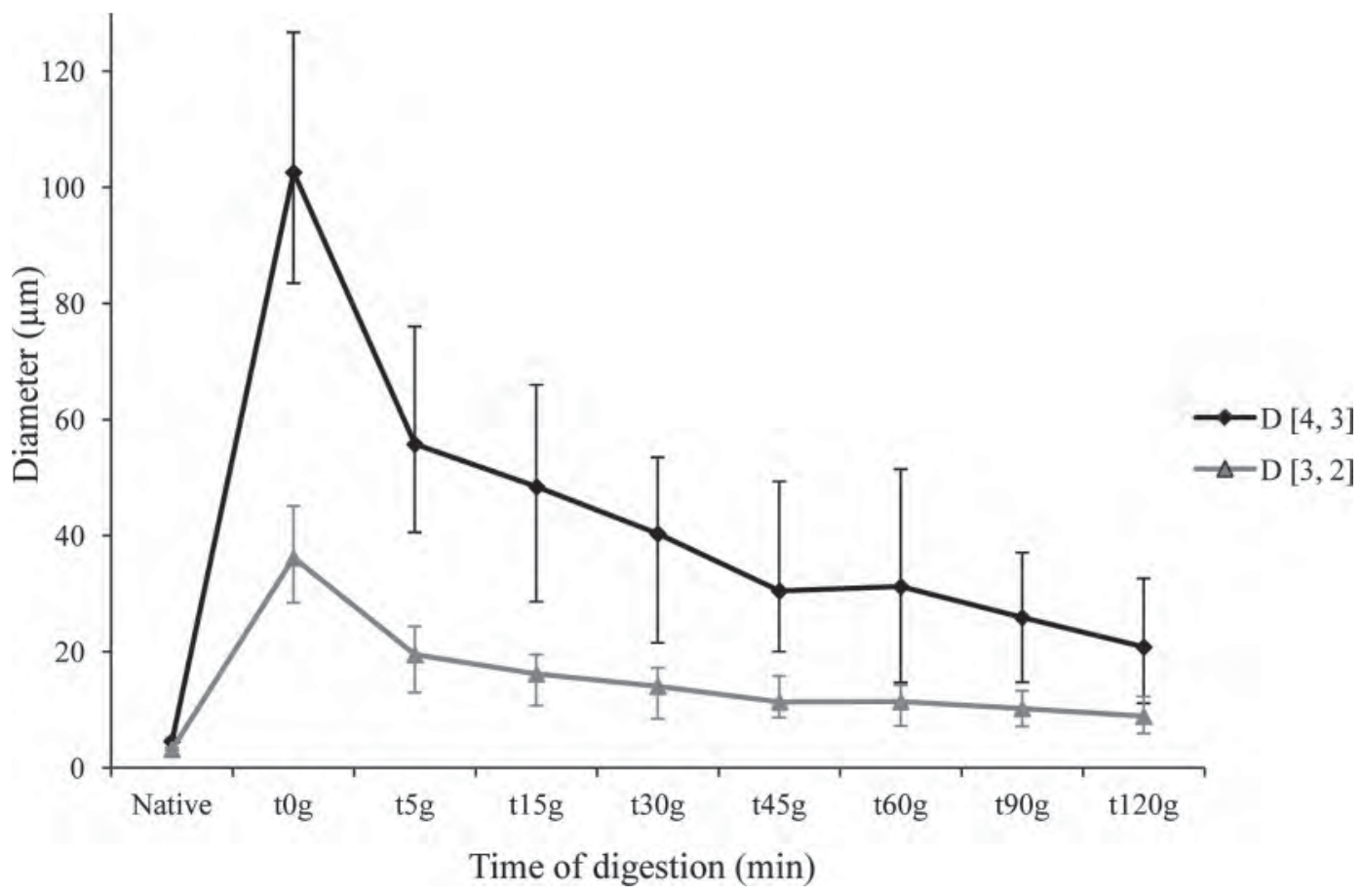

Figure 3. Volume mean (D $[4,3])$ and surface mean (D [3, 2]) diameters of bovine milk (native) and digested samples [from 0 (t0g) to 120 $(\mathrm{t} 120 \mathrm{~g})$ min of gastric digestion with pepsin]. 
Microstructural Changes. The gastric digestion of bovine milk was followed with confocal laser scanning microscopy (CLSM) (Figure 4). Caseins and whey proteins aggregated under low-acidic conditions (Figures 4A, 4C, 4E, 4F, 4G, and 4H). Some milk fat globules were trapped inside the aggregates (Figures $4 \mathrm{E}$ and $4 \mathrm{H})$. No coalescence of the fat globules was observed, meaning that the MFGM stabilized the globules throughout digestion. The $\mathrm{d}_{43}$ and $\mathrm{d}_{32}$ values (Figure 3 ) were, thus, sensitive to the presence of protein aggregates. Ye et al. (2011) showed that peptides, resulting from the proteolysis of MFGM proteins by pepsin, remained attached to the surface of the milk fat globules throughout gastric digestion. The lateral distribution of the phospholipids at the surface of the fat globules did not seem to be altered by the low-acidic $\mathrm{pH}$ and the hydrolysis of the MFGM proteins by pepsin, as MFGM phospholipids were still present at the interface after 120 min of gastric digestion and liquid-ordered domains were still observed during digestion (Figures 4B, 4D, and $4 \mathrm{I})$.

Gallier (2010) observed a change in the shape and size of the liquid-ordered domains upon heating or cooling of the milk fat globules. Indeed, temperature has been shown to influence the shape, number and size of the liquid-ordered domains in model membrane systems (Dietrich et al., 2001; de la Serna et al., 2004). Therefore, as the presence of liquid-ordered domains may influence the binding of enzymes as stated earlier, the increased number of liquid-ordered domains upon heating of the milk from $4^{\circ} \mathrm{C}$ (storage temperature) to $37^{\circ} \mathrm{C}$ (physiological temperature; Gallier, 2010) may limit or slow down the digestion of the milk fat globules.

$\boldsymbol{\zeta}$-Potential. The $\zeta$-potential of native and digested bovine milk fat globules was monitored. The $\zeta$-potential of bovine milk fat globules is highly negative $(-35.5$ $\mathrm{mV}$ ) near neutral $\mathrm{pH}$. The presence of a glycocalyx, made of glycoproteins and glycolipids, at the surface of the MFGM provides a steric barrier that prevents the milk fat globules from coalescing and aggregating (van Aken, 2010). When the milk was mixed with SGF and the $\mathrm{pH}$ was adjusted to 1.5 , the $\zeta$-potential became highly positive $(30.5 \mathrm{mV})$, because the $\mathrm{pH}$ was well below the isoelectric point of the MFGM proteins. However, the MFGM proteins may have remained attached to the surface of the milk fat globules, as the absolute $\zeta$-potentials in the native state and at $\mathrm{pH} 1.5$ were relatively similar. The high positive charge of the MFGM proteins provided sufficient electrostatic repulsion between the fat globules, preventing their coalescence or flocculation at $\mathrm{pH} 1.5$ (Figure 4). The $\zeta$-potential of the fat globules remained fairly constant between 30.5 and $36.3 \mathrm{mV}$ throughout the $2 \mathrm{~h}$ of gastric digestion with pepsin, suggesting that the peptic digests carried a similar positive charge to the MFGM proteins. The peptides were also surface active enough to remain at the interface and provide a sufficient steric barrier to prevent coalescence or flocculation of the globules during gastric digestion (Figure 4). In addition, some of the MFGM proteins are partially resistant to proteolysis by pepsin. The high degree of glycosylation of human and bovine MFGM plays a role in the inhibition of enzymatic proteolysis (Shimizu et al., 1982; Hamosh et al., 1999; Vanderghem et al., 2011). Therefore, the presence of intact or partially hydrolyzed MFGM glycoproteins contributed to the highly positive $\zeta$-potential during gastric digestion. Milk fat globule membrane phospholipids (Figure 4), glycoproteins, and peptides stabilized the fat globules during gastric digestion.

\section{Gastric Digestion Followed by Intestinal Digestion}

Protein Hydrolysis. Figure 5 presents the SDSPAGE patterns of bovine milk proteins after $1 \mathrm{~h}$ of gastric digestion with pepsin and $2 \mathrm{~h}$ of intestinal digestion with pancreatin and bile salts. At intestinal $\mathrm{pH}$, pepsin is not active (Boyer, 1971). Most of the pepsin-resistant milk proteins and peptides were completely digested at the end of the full digestion (Figure 5). However, trypsin and chymotrypsin, the main pancreatic proteases, were not able to complete the hydrolysis of all milk proteins, as $\beta$-LG and a few pepsin-resistant peptides were still detected at the end of the digestion but in a lower concentration, as the band intensities decreased over the time of digestion (Figure 5). Butyrophilin is more resistant than xanthine oxidase and PAS 6/7 to pepsin (Ye et al., 2011), but is completely hydrolyzed by trypsin, whereas xanthine oxidase is almost resistant to trypsin (Vanderghem et al., 2011).

Particle Size Distribution. The particle size distribution of digested milk fat globules was studied (Figure 6). After $1 \mathrm{~h}$ of gastric digestion, the particle size distribution was bimodal, with particles of between 2 and $15 \mu \mathrm{m}$ and between 20 and $160 \mu \mathrm{m}$ in size. It remained bimodal when the pregastric digested milk was mixed with SIF and bile salts at $\mathrm{pH} 7$; however, the particles were smaller (between 0.7 and $2 \mu \mathrm{m}$ and 2 and $50 \mu \mathrm{m}$; Figure 6). After $5 \mathrm{~min}$ of intestinal digestion, slightly fewer small particles were detected but a few very large particles (40 to $180 \mu \mathrm{m}$ in size) appeared (Figure 6). As bile salts had been added and lipolysis was occurring, the milk fat globules were destabilized, leading to globule coalescence and an increase in size of the globules. As the intestinal digestion proceeded, more large globules and fewer globules between 2.5 and $30 \mu \mathrm{m}$ were detected (Figure 6 ), suggesting that more globules were destabilized and coalesced. Further proteolysis of membrane proteins by intestinal proteases, 

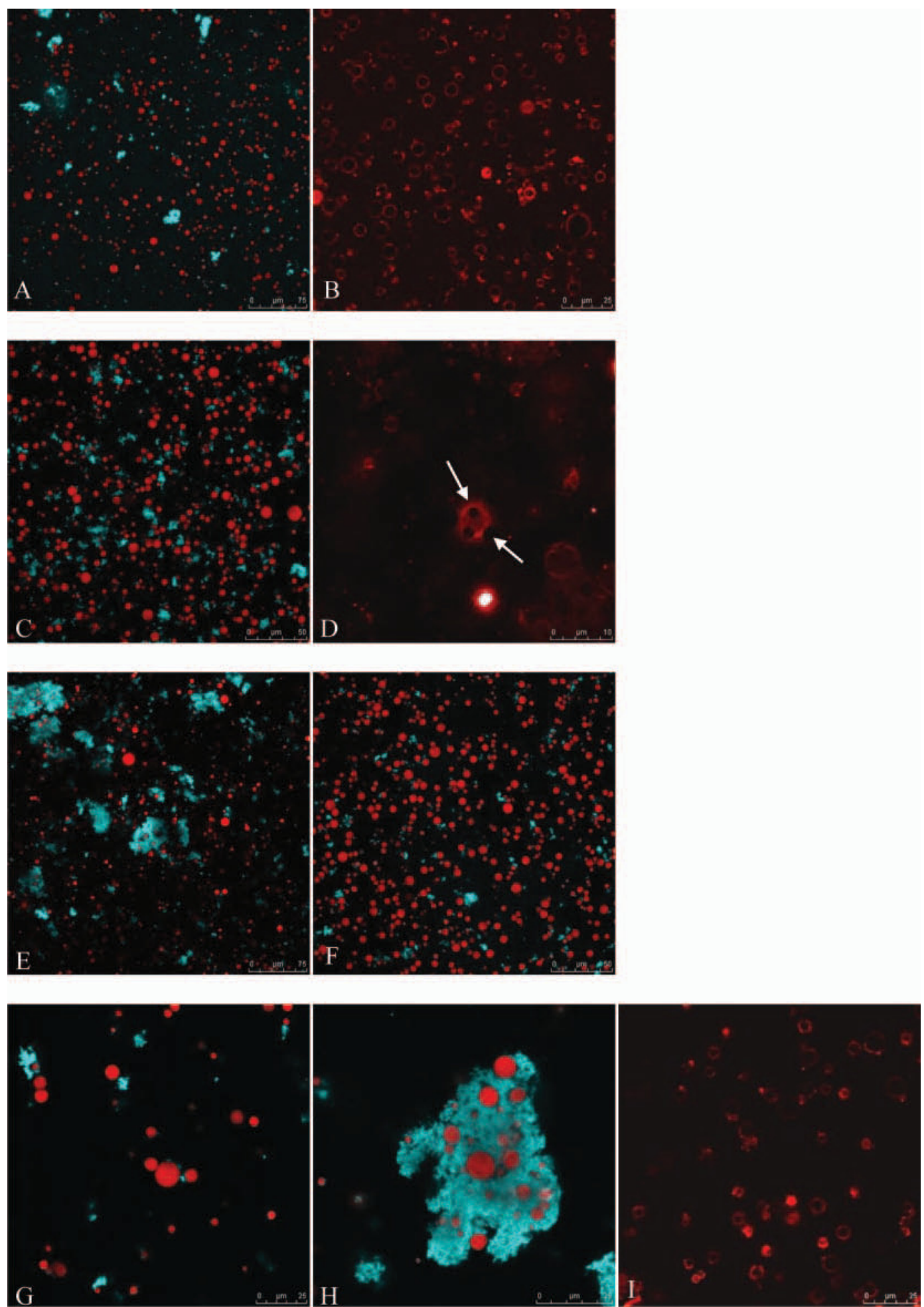

Figure 4. Confocal laser scanning microscopy images of native (A and B) and digested $[\mathrm{C}$ and $\mathrm{D}(15 \mathrm{~min}), \mathrm{E}(30 \mathrm{~min}), \mathrm{F}$ (60 min), and $\mathrm{G}$ to I (120 min)] bovine milk fat globules under simulated gastric conditions with ( $\mathrm{C}$ to I) or without (A and B) pepsin. The triglyceride core of the fat globules was stained with Nile Red (A, C, and E to H), the milk proteins were stained with Fast Green FCF, and the milk fat globule membrane phospholipid distribution was revealed by staining with Lissamine rhodamine B 1,2-dihexadecanoyl-sn-glycero-3-phosphoethanolamine $(\mathrm{B}, \mathrm{D}$, and I). The white arrows point at liquid-ordered domains. Scale bars $=10 \mu \mathrm{m}(\mathrm{D}), 25 \mu \mathrm{m}(\mathrm{B}, \mathrm{G}$ to I), $50 \mu \mathrm{m}(\mathrm{C}$ and F), and $75 \mu \mathrm{m}(\mathrm{A}$ and $\mathrm{E}$ ). Color version in the online PDF. 


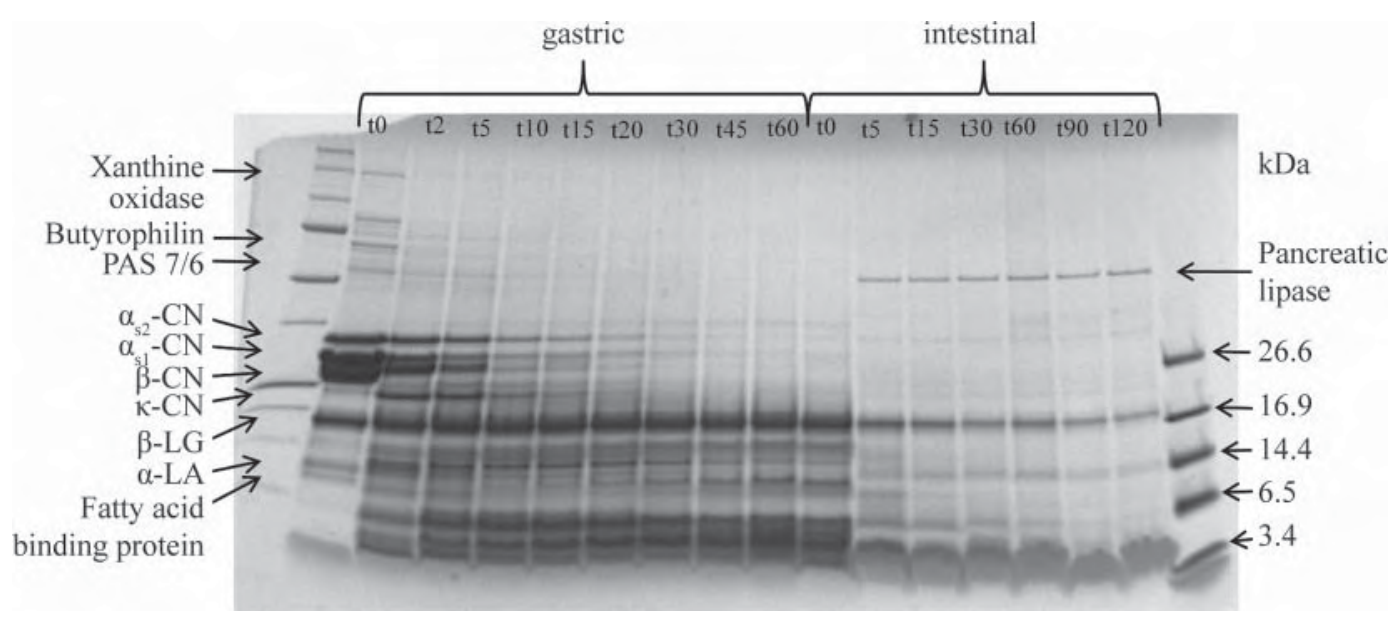

Figure 5. Reducing tricine-SDS-PAGE patterns of bovine milk and digested samples under gastric conditions $(1 \mathrm{~h})$ followed by intestinal conditions $(2 \mathrm{~h}) . \mathrm{PAS}=$ periodic acid-Schiff.

adsorption of bile salts onto the globule surface, and lipolysis of triglycerides producing surface-active products led to a change in the stability and the diameter of the globules.

The $\mathrm{d}_{43}$ and $\mathrm{d}_{32}$ values were also determined (Figure $7) ; d_{43}$ was sensitive to the presence of coalesced globules and $d_{32}$ was sensitive to the mixed bile salt-phospholipid micelles. Upon mixing the pregastric digested milk with SIF and bile salts at $\mathrm{pH} 7$, both $\mathrm{d}_{43}$ and $\mathrm{d}_{32}$ decreased considerably, as the aggregates observed under gastric conditions (Figures 2 and 3 ) were broken down by the action of bile salts and the increase in $\mathrm{pH}$ from 1.5 to 7 . During intestinal digestion, $\mathrm{d}_{43}$ increased as more globules coalesced and $\mathrm{d}_{32}$ increased only very slightly, as the size of the micelles remained the same throughout intestinal digestion (Figure 7). The particle

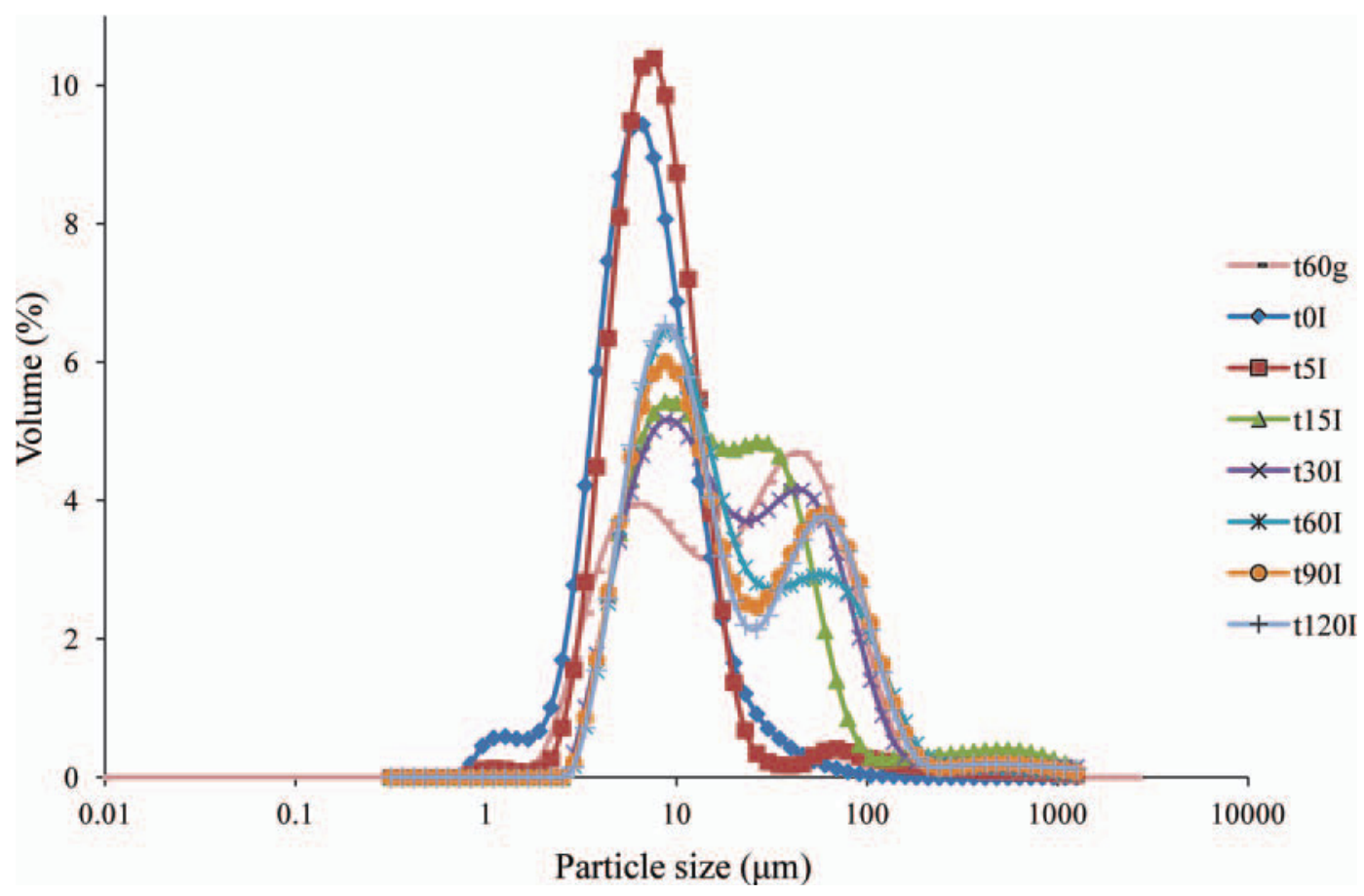

Figure 6. Particle size distribution of bovine milk fat globules after $60 \mathrm{~min}$ of gastric digestion ( $\mathrm{t} 60 \mathrm{~g}$ ) followed by $2 \mathrm{~h}$ of intestinal digestion (t0I to t120I). Color version in the online PDF. 


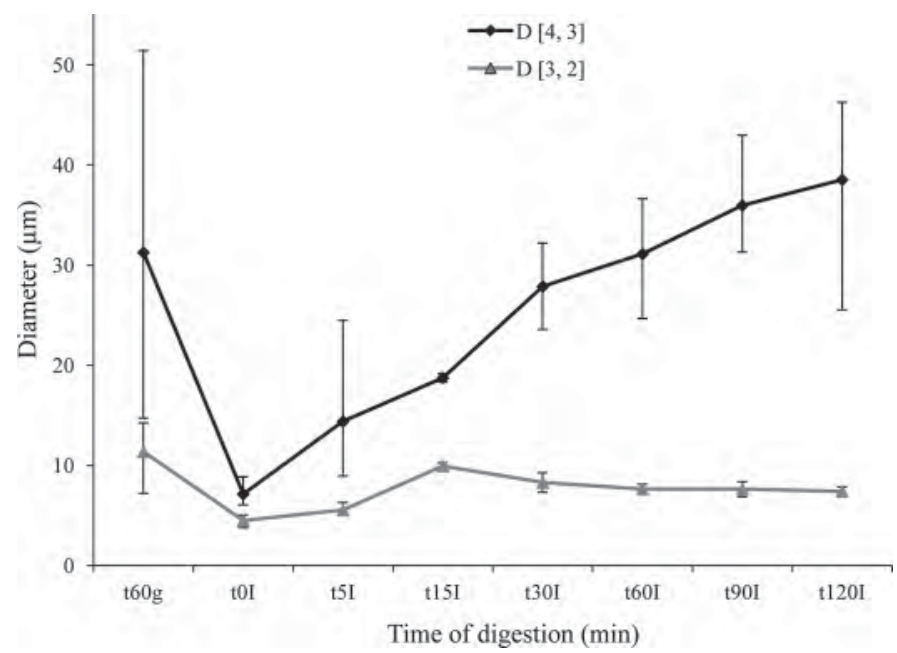

Figure 7. Volume mean $(\mathrm{D}[4,3])$ and surface mean $(\mathrm{D}[3,2])$ diameters of bovine milk fat globules after $60 \mathrm{~min}$ of gastric digestion (t60g), followed by $2 \mathrm{~h}$ of intestinal digestion (t0I to t120I).

size of oil-in-water emulsions is usually between 1 and $50 \mu \mathrm{m}$ in the small intestine (Singh et al., 2009), as observed in Figure 7.

$\boldsymbol{\zeta}$-Potential. The $\zeta$-potential of milk fat globules after $1 \mathrm{~h}$ of gastric digestion and during $2 \mathrm{~h}$ of intestinal digestion was monitored. When the pregastric digested milk was mixed with SIF and bile extracts at $\mathrm{pH} 7$, the interface of the fat globules was altered and the surface charge became negative, as the $\mathrm{pH}$ was probably above the isoelectric point of the pepsin-resistant proteins and peptides, and the bile salts displaced the proteins, peptides, and phospholipids from the interface of the globules. At $\mathrm{pH} 7$, bile salts carry a highly negative charge (van Aken, 2010). However, at 0 min of intestinal digestion, the charge on the fat globules was only $-13.5 \mathrm{mV}$, suggesting that the bile salts did not fully displace the MFGM components. Once pancreatin was added, trypsin and chymotrypsin further hydrolyzed the proteins and peptides of the milk and pancreatic lipase hydrolyzed the triglyceride molecules into FFA and monoglycerides, which accumulated at the interface. The accumulation of lipolytic products at the interface of the globules led to a rapid decrease in the $\zeta$-potential at $5 \mathrm{~min}$ of digestion $(-33.5 \mathrm{mV})$, as FFA are partially deprotonated at pH 7 (van Aken, 2010). After 15 min, the $\zeta$-potential decreased only slightly (from $-33.5 \mathrm{mV}$ to $-42.1 \mathrm{mV}$ ), as the lipolytic products, at the same time as being formed, were removed from the interface by being solubilized into mixed bile salt-phospholipid micelles and phospholipid vesicles.

FFA Release. The release of titrable FFA from milk fat globules during intestinal digestion preceded by gastric proteolysis was measured by titration (Figure
8). No lag phase was observed, indicating that the bile salts efficiently displaced some pepsin-digested residual MFGM material, colipase adsorbed quickly on to the bile-salt-covered interfacial areas, and pancreatic lipase bound to colipase and was activated within seconds after addition to the pregastric digested milk mixed with bile extracts and SIF. Lipolysis was very fast in the first $5 \mathrm{~min}$, with $30 \mu \mathrm{mol}$ of FFA released $/ \mathrm{mL}$ (Figure 8 ), denoting a readily accessible interface. The rapid lipolysis led to an accumulation of lipolytic products at the surface of the globules. This interfacial saturation slowed down the rate of lipolysis (Figure 8) as the triglyceride core became less accessible to pancreatic lipase until bile salts and phospholipids were able to solubilize the lipolytic products into micelles. Bovine milk lipids contain more than two-thirds SCFA and MCFA (Jensen and Newburg, 1995); as SCFA and MCFA lipolytic products have a high dispersibility in aqueous media, they migrate rapidly from the oil-water interface to the aqueous phase and do not inhibit further hydrolysis of triglycerides by pancreatic lipase ( $\mathrm{Li}$ et al., 2011).

About $114 \mu \mathrm{mol}$ of $\mathrm{FFA} / \mathrm{mL}$ was released after back titration at $2 \mathrm{~h}$ of intestinal digestion preceded by gastric digestion (Figure 8). The release of FFA (Figure 8) was improved in comparison with the release of FFA during the lipolysis of raw bovine milk fat globules that were not predigested by pepsin (Ye et al., 2010). This suggests that a prehydrolysis of MFGM proteins enhances the activity of pancreatic lipase on raw bovine milk fat globules. It must be kept in mind that pancreatin is a mix of pancreatic enzymes and, therefore, also contains phospholipases, which are capable of releasing FFA from phospholipids, and cholesterol ester lipase, which is capable of producing FFA from triglycerides,

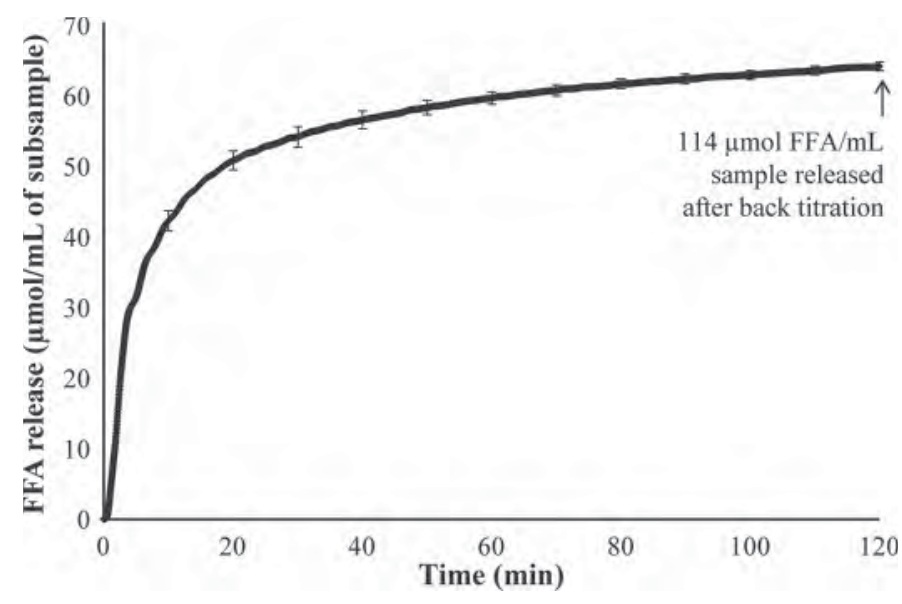

Figure 8. Free FA release from bovine milk fat globules during $2 \mathrm{~h}$ of intestinal digestion preceded by $1 \mathrm{~h}$ of gastric digestion. 
phospholipids, vitamins, and cholesterol esters (Brockerhoff and Jensen, 1974). However, pancreatic lipase is the dominant pancreatic enzyme. A lag phase during the hydrolysis of milk fat globules by pancreatic lipase was observed by Berton et al. (2009) and was associated with the presence of phospholipids at the surface of the globules. However, the native milk fat globules were not subjected to pregastric digestion. Therefore, in this present study, the pregastric proteolysis of the native milk fat globules may have allowed destabilization of the MFGM phospholipid packing and its easier disruption by bile salts, which abolished the lag phase (Figure 8). Indeed, proteins play a key role in the lateral organization of MFGM phospholipids (Gallier et al., 2011) and their hydrolysis may alter the structural arrangement of the phospholipids.

Microstructural Changes. Confocal laser scanning microscopy was used to observe the structure of the milk fat globules during intestinal digestion preceded by gastric digestion (Figure 9). When the pepsin-digested milk was mixed with SIF and bile salts, phospholipids and a few glycoproteins were still detected at the surface of the globules (Figure 9A), probably explaining the stabilization of the bovine milk fat globules during gastric digestion and the addition of bile salts. Native MFGM contains glycoproteins; however, after proteolysis by pepsin and the addition of bile salts, only very few glycoproteins were still detected (Figure 9A). As $\beta$-LG and other pepsin-resistant peptides were not fully hydrolyzed by trypsin and chymotrypsin (Figure 5 ), some protein aggregates were still detected under intestinal conditions (Figures 9B and 9C).

After 15 min of intestinal digestion, a liquid-crystalline lamellar phase was formed at the surface of some fat globules (Figures 9D to 9O). The formation of this liquid-crystalline lamellar phase, rich in FA and calcium, was first reported by Patton and Carey (1979) and was further characterized by the same group (Rigler and Patton, 1983; Rigler et al., 1986). The surface of the oil droplets became crenated and the shell around the droplets became thicker, as seen in Figures 9D and 9M and by Patton and Carey (1979). The liquid-crystalline phase was associated with the accumulation of lipolytic products and the formation of vesicles carrying the lipolytic products for later transport from the interface of the globules to the aqueous phase and through the intestinal wall. Rigler et al. (1986) described the aggregated lipolytic product phase as multiple-layer formations or lamellae with water spacing, as seen in Figures $9 \mathrm{G}$ and $9 \mathrm{~L}$, respectively.

After 15 min of intestinal digestion, large coalesced fat globules appeared and microparticles of various sizes, probably containing amphiphiles, as they were stained with Rd-DHPE, were present in the aqueous phase (Figures 9D to 9O). These microparticles were probably mixed bile salt-phospholipid micelles transporting the FFA. Indeed, bile salts form disk-shaped micelles upon addition of lipolytic products (Rigler et al., 1986; Maldonado-Valderrama et al., 2011). The literature values for the size of the micelles transporting the lipolytic products seems to vary, from 18 to 3,000 $\mathrm{nm}$ (Rigler et al., 1986) and 3 to $10 \mu \mathrm{m}$ (Hofmann and Borgstrom, 1962) in in vitro studies to a few nanometers in in vivo studies (Carey et al., 1983). The gentle stirring in this study, to simulate the calmness of the fundus in the presence of liquid food and the low mechanical energy in the duodenum (Armand et al., 1999), may contribute to coalescence of the micelles. Another possible explanation for the absence of nanometer-sized micelles and the presence of micrometer-sized micelles could be the accumulation of these micelles in the reactor in vitro, leading to their coalescence, whereas in vivo these micelles are absorbed through the intestinal walls after formation.

As observed in this study, bovine milk fat globules maintain their structural integrity under gastric conditions, whereas their membrane is displaced by bile salts and the globules disintegrate in the simplified duodenal-like conditions, similarly to human milk fat globules (Hamosh, 1990). Bovine MFGM glycoproteins and phospholipids play a key role in the stabilization and protection of the milk fat globules during gastrointestinal digestion. A synergy exists between enzymes, colipase, and bile salts for efficient lipolysis of bovine milk fat globules. Without hydrolysis of MFGM proteins by trypsin, pancreatic lipase is not able to hydrolyze the triglyceride core of the globules (Shimizu et al., 1982). The C-terminal domain of pancreatic lipase interacts with the colipase, whereas the N-terminal domain contains the catalytic triad (Berton et al., 2009). Conjugated bile salts, in concentrations found in vivo, are capable of displacing some MFGM material from the surface of the globules (Patton et al., 1986). Then, they adsorb on to the surface and participate in the onset of lipolysis through interaction with the complex colipaselipase. In phospholipid-stabilized emulsions, there is then coexistence between phospholipid-rich regions and bile-salt-rich regions at the oil-water interface (Verger, 1997). In the phospholipid monolayer model system, after the addition of bile salts, the complex colipaselipase will bind only to liquid expanded phospholipidbile salt regions and not to liquid condensed regions (Maldonado-Valderrama et al., 2011). This suggests that the complex colipase-lipase is not able to bind to liquid-ordered domains, rich in sphingomyelin and cholesterol, present at the surface of the milk fat globules 

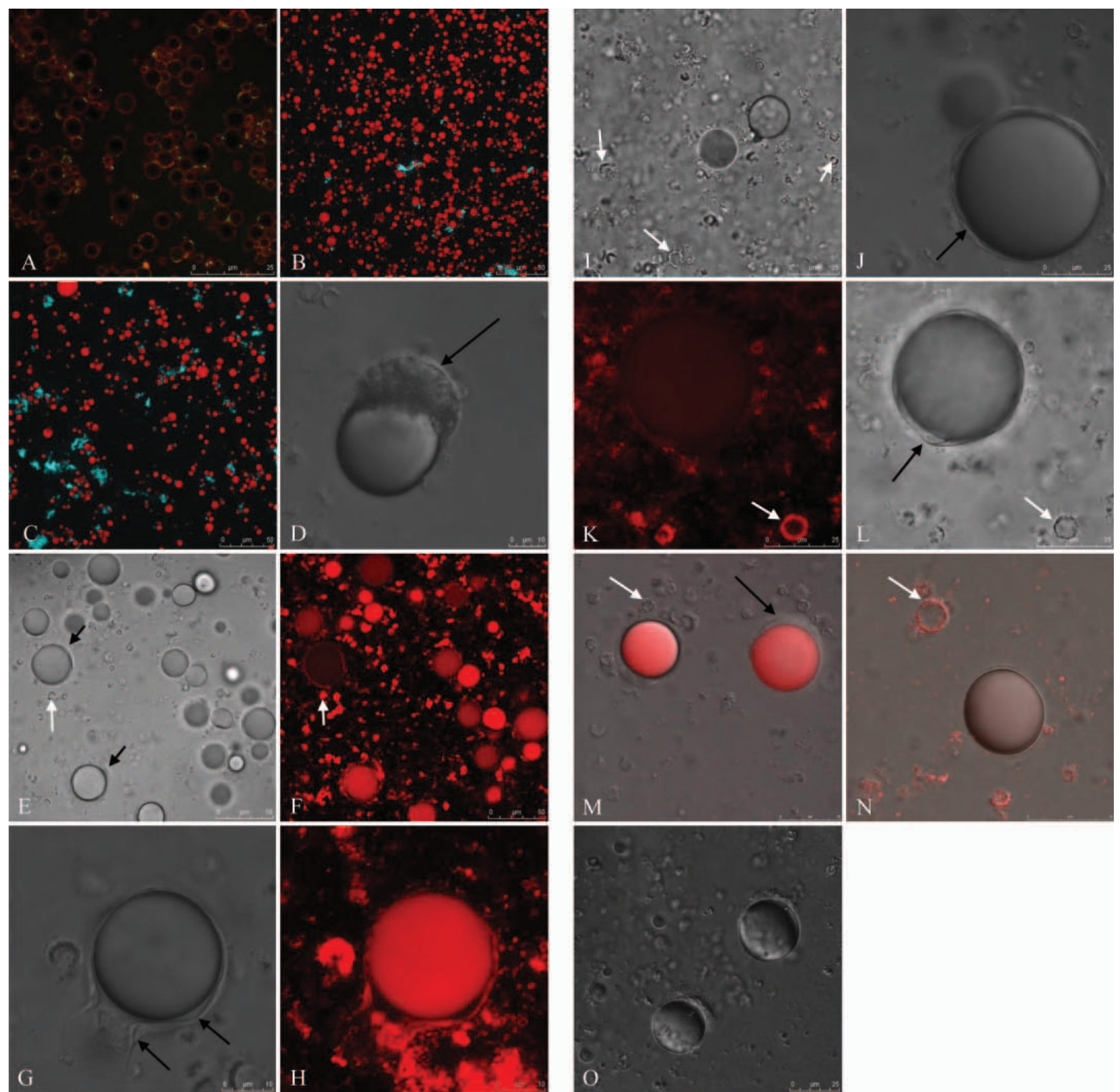

Figure 9. Confocal laser scanning microscopy and differential interference contrast-polarization (DIC-Pol) images of pregastric digested milk fat globules under simulated intestinal conditions for $2 \mathrm{~h}$ with [C to $\mathrm{H}$ (15 min), I to L (30 min), $\mathrm{M}$ and $\mathrm{N}$ (60 min), and $\mathrm{O}$ (120 min)] or without (A and B) pancreatin. The triglyceride core was stained with Nile Red (B, C, and M), the proteins were stained with Fast Green FCF (B and C), the glycoproteins were stained with wheat germ agglutinin (A), and the phospholipids were stained with Lissamine rhodamine B 1,2-dihexadecanoyl-sn-glycero-3-phosphoethanolamine (Rd-DHPE; A, F, H, K, and N). The black arrows point at liquid-crystalline phases and the white arrows point at micelles. Scale bars $=10 \mu \mathrm{m}(\mathrm{D}, \mathrm{G}$, and H), $25 \mu \mathrm{m}$ (A, I to O), and $50 \mu \mathrm{m}(\mathrm{B}, \mathrm{C}, \mathrm{E}$, and F). Color version in the online PDF.

(Gallier et al., 2010). Based on the above discussion, we propose a working model of digestion of the bovine milk fat globules (Figure 10). This model is valid for low-
$\mathrm{pH}$ values in the gastric environment in which gastric lipase has very little to no activity. The implication of the liquid-ordered domains in intestinal conditions 


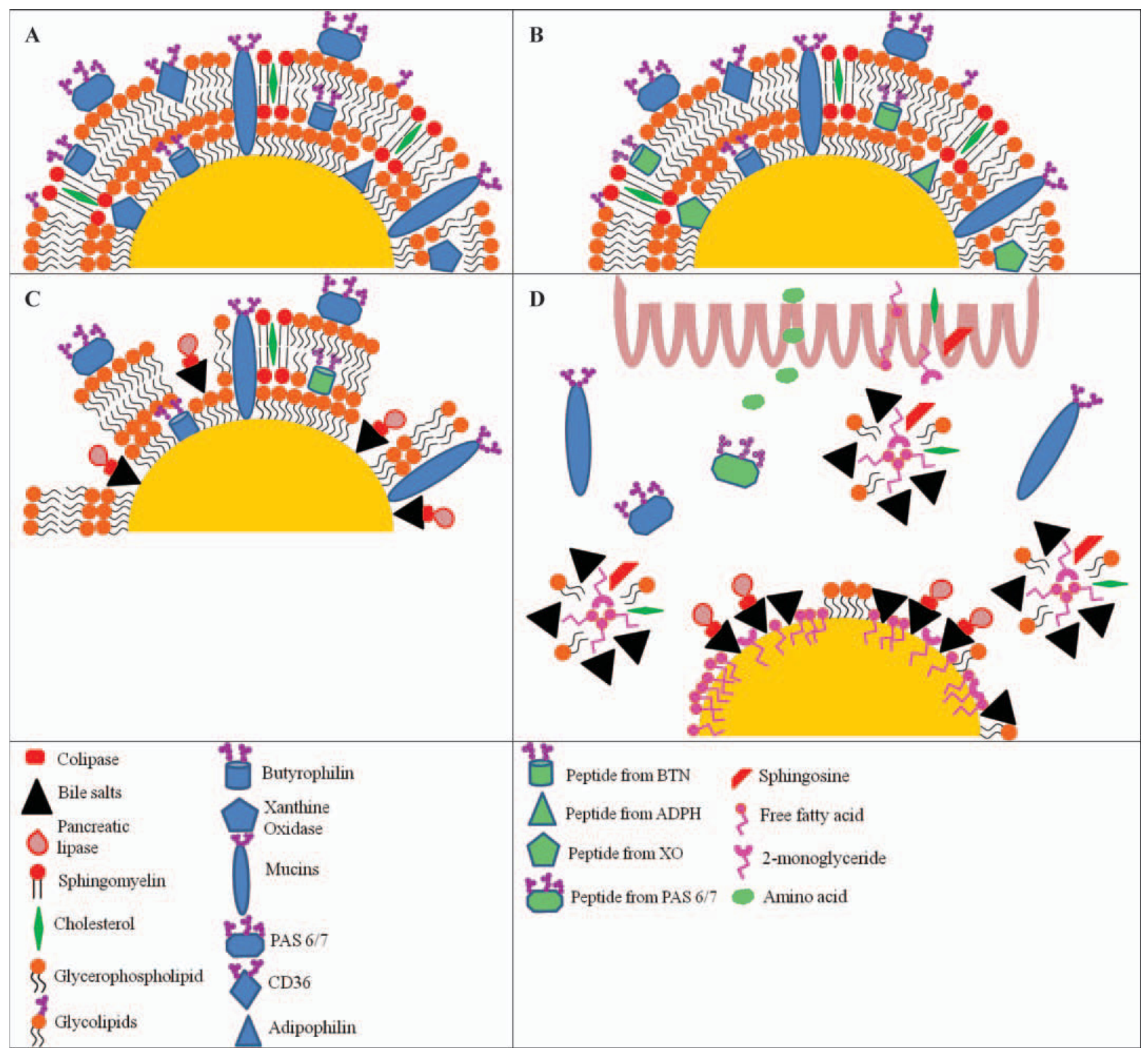

Figure 10. Schematic diagram illustrating the interfacial changes occurring at the surface of the milk fat globule during gastric and intestinal digestion. (A) Native milk fat globule membrane (MFGM) structure. A phospholipid trilayer embedding proteins. (B) Milk fat globule in gastric environment at $\mathrm{pH}<2$. Pepsin hydrolyzes MFGM proteins at different rates and some MFGM glycoproteins are resistant to proteolysis; the resulting peptides are surface active enough to remain at the interface. (C) Beginning of the intestinal digestion. The bile salts displace the phospholipids, proteins, and peptides and adsorb onto the interface. The colipase adsorbs on to the bile-salt-rich interface and the pancreatic lipase forms a complex with the colipase. (D) Trypsin and chymotrypsin hydrolyze some of the MFGM proteins and peptides into amino acids, which further absorb through the intestinal wall; most of the mucins and part of periodic acid-Schiff (PAS) 6/7 are resistant to proteolysis. The pancreatic lipase hydrolyzes the triglyceride core, and lipolytic products accumulate at the oil-water interface and are then solubilized into mixed phospholipid-bile salt micelles for their transport through the intestinal wall. Cholesterol molecules are similarly transported. CD36 $=$ cluster of differentiation 36; BTN = butyrophilin; ADPH = adipophilin. Not to scale. Color version in the online PDF.

is not yet known, but intestinal sphingomyelinase will hydrolyze sphingomyelin molecules into ceramides and phosphorylcholine residues. Ceramides will be further hydrolyzed into sphingosine and FFA by cholesterol ester lipase (Nyberg et al., 1998). Cholesterol molecules will be solubilized into mixed micelles and phospholipid vesicles and transported into chylomicrons (Armand, 2008). 


\section{CONCLUSIONS}

Raw bovine milk was subjected to a 2 -step in vitro digestion. Under gastric conditions, pepsin was not able to hydrolyze completely all of the milk proteins, as a few milk proteins, in particular $\beta-\mathrm{LG}$, and pepsin-resistant peptides were still detected after $2 \mathrm{~h}$ of gastric digestion. Pancreatic proteases were also not successful at hydrolyzing all $\beta$-LG molecules. The native milk fat globules were stable to coalescence or aggregation under simulated gastric conditions, whereas coalescence of fat globules occurred under simulated intestinal conditions, as lipolysis by pancreatic lipase proceeded. At a sufficient ratio of lipolytic products to bile salts, liquid-crystalline lamellae appeared at the surface of the milk fat globules and disk-shaped bile salt-phospholipid micelles formed in the aqueous phase, transporting the lipolytic products. This study shows the importance of the MFGM structure in the digestion of the milk fat globules. Therefore, any processing treatment affecting the MFGM structure will influence the way milk fat globules are digested. Nutritionally functional food should be designed in a way to simulate the native MFGM. Further work on the composition of the micellar phase is under way in our laboratory.

\section{ACKNOWLEDGMENTS}

The authors thank Erin Doherty (California Polytechnic State University, San Luis Obispo, CA) for her help in carrying out the laboratory experiments. The work was supported by a Centre of Research Excellence fund from the Tertiary Education Commission and the Ministry of Education, New Zealand.

\section{REFERENCES}

Anderson, M., and B. E. Brooker. 1975. Loss of material during isolation of milk-fat globule membrane. J. Dairy Sci. 58:1442-1448.

Armand, M. 2007. Lipases and lipolysis in the human digestive tract: Where do we stand? Curr. Opin. Clin. Nutr. Metab. Care 10:156164.

Armand, M. 2008. Milk fat digestibility. Sci. Aliments 28:84-98.

Armand, M., B. Pasquier, M. André, P. Borel, M. Senft, J. Peyrot, J. Salducci, H. Portugal, V. Jaussan, and D. Lairon. 1999. Digestion and absorption of 2 fat emulsions with different droplet sizes in the human digestive tract. Am. J. Clin. Nutr. 70:1096-1106.

Baumrucker, C. R., and T. W. Keenan. 1973. Membranes of mammary gland. VII. Stability of milk fat globule membrane in secreted milk. J. Dairy Sci. 56:1092-1094.

Berton, A., C. Sebban-Kreuzer, S. Rouvellac, C. Lopez, and I. Crenon. 2009. Individual and combined action of pancreatic lipase and pancreatic lipase-related proteins 1 and 2 on native versus homogenized milk fat globules. Mol. Nutr. Food Res. 53:1592-1602.

Bonnaire, L., S. Sandra, T. Helgason, E. A. Decker, J. Weiss, and D. J. McClements. 2008. Influence of lipid physical state on the in vitro digestibility of emulsified lipids. J. Agric. Food Chem. 56:3791-3797.

Boyer, P. D. 1971. The Enzymes. Academic Press, New York, NY.
Brockerhoff, H., and R. G. Jensen. 1974. Lipolytic Enzymes. Academic Press, New York, NY.

Carey, M. C., D. M. Small, and C. M. Bliss. 1983. Lipid digestion and absorption. Annu. Rev. Physiol. 45:651-677.

de la Serna, J. B., J. Perez-Gil, A. C. Simonsen, and L. A. Bagatolli. 2004. Cholesterol rules-Direct observation of the coexistence of two fluid phases in native pulmonary surfactant membranes at physiological temperatures. J. Biol. Chem. 279:40715-40722.

Dietrich, C., L. A. Bagatolli, Z. N. Volovyk, N. L. Thompson, M. Levi, K. Jacobson, and E. Gratton. 2001. Lipid rafts reconstituted in model membranes. Biophys. J. 80:1417-1428.

Gallier, S. 2010. Understanding the structure of the bovine milk fat globule and its membrane by means of microscopic techniques and model systems. PhD Thesis. University of Otago, Dunedin, New Zealand.

Gallier, S., D. Gragson, R. Jimenez-Flores, and D. Everett. 2010. Using confocal laser scanning microscopy to probe the milk fat globule membrane and associated proteins. J. Agric. Food Chem. 58:4250-4257.

Gallier, S., D. Gragson, R. Jiménez-Flores, and D. W. Everett. 2011. $\beta$-Casein-phospholipid monolayers as model systems to understand lipid-protein interactions in the milk fat globule membrane. Int. Dairy J. 22:58-65.

Gargouri, Y., G. Pieroni, P. A. Lowe, L. Sarda, and R. Verger. 1986. Human gastric lipase The effect of amphiphiles. Eur. J. Biochem. 156:305-310.

Hamosh, M. 1990. Role of lingual and gastric lipases in fat digestion and absorption. Pages 179-227 in Lingual and Gastric Lipases: Their Role in Fat Digestion. M. Hamosh, ed. CRC Press, Boca Raton, FL.

Hamosh, M., J. A. Peterson, T. R. Henderson, C. D. Scallan, R. Kiwan, R. L. Ceriani, M. Armand, N. R. Mehta, and P. Hamosh. 1999. Protective function of human milk: The milk fat globule. Semin. Perinatol. 23:242-249.

Hofmann, A. F., and B. Borgstrom. 1962. Physico-chemical state of lipids in intestinal content during their digestion and absorption. Fed. Proc. 21:43-50.

Jensen, R. G., and D. S. Newburg. 1995. Bovine Milk Lipids. Pages 543-575 in Handbook of Milk Composition. R. G. Jensen, ed. Academic Press, San Diego, CA.

Li, Y., M. Hu, and D. J. McClements. 2011. Factors affecting lipase digestibility of emulsified lipids using an in vitro digestion model: Proposal for a standardised pH-stat method. Food Chem. 126:498-505.

Lopez, C. 2011. Milk fat globules enveloped by their biological membrane: Unique colloidal assemblies with a specific composition and structure. Curr. Opin. Colloid Interface Sci. 16:391-404.

Lopez, C., M. N. Madec, and R. Jimenez-Flores. 2010. Lipid rafts in the bovine milk fat globule membrane revealed by the lateral segregation of phospholipids and heterogeneous distribution of glycoproteins. Food Chem. 120:22-33.

Maldonado-Valderrama, J., P. Wilde, A. Macierzanka, and A. Mackie. 2011. The role of bile salts in digestion. Adv. Colloid Interface Sci. 165:36-46.

McClements, D. J., E. A. Decker, Y. Park, and J. Weiss. 2008. Designing food structure to control stability, digestion, release and absorption of lipophilic food components. Food Biophys. 3:219-228.

Michalski, M.-C. 2009. Specific molecular and colloidal structures of milk fat affecting lipolysis, absorption and postprandial lipemia. Eur. J. Lipid Sci. Technol. 111:413-431.

Michalski, M.-C., F. Michel, D. Sainmont, and V. Briard. 2002. Apparent $\zeta$-potential as a tool to assess mechanical damages to the milk fat globule membrane. Colloids and Surfaces B Biointerfaces $23: 23-30$.

Michalski, M.-C., M. Ollivon, V. Briard, N. Leconte, and C. Lopez. 2004. Native fat globules of different sizes selected from raw milk: Thermal and structural behavior. Chem. Phys. Lipids 132:247261.

Mun, S., E. A. Decker, and D. J. McClements. 2007. Influence of emulsifier type on in vitro digestibility of lipid droplets by pancreatic lipase. Food Res. Int. 40:770-781. 
N'Goma, J.-C. B., S. Amara, K. Dridi, V. Jannin, and F. Carrière. 2012. Understanding the lipid-digestion processes in the GI tract before designing lipid-based drug-delivery systems. Therapeutic Delivery 3:105-124.

Nyberg, L., A. Farooqi, L. Bläckberg, R.-D. Duan, Å. Nilsson, and O. Hernell. 1998. Digestion of ceramide by human milk bile saltstimulated lipase. J. Pediatr. Gastroenterol. Nutr. 27:560-567.

Patton, J. S., and M. C. Carey. 1979. Watching fat digestion. Science 204:145-148

Patton, S., B. Borgström, B. H. Stemberger, and U. Welsch. 1986. Release of membrane from milk fat globules by conjugated bile salts. J. Pediatr. Gastroenterol. Nutr. 5:262-267.

Patton, S., and T. W. Keenan. 1975. The milk fat globule membrane. Biochim. Biophys. Acta 415:273-309.

Rigler, M. W., R. E. Honkanen, and J. S. Patton. 1986. Visualization by freeze-fracture, in vitro and in vivo, of the products of fat digestion. J. Lipid Res. 27:836-857.

Rigler, M. W., and J. S. Patton. 1983. The production of liquid-crystalline product phases by pancreatic lipase in the absence of bile salts. A freeze-fracture study. Biochim. Biophys. Acta 751:444454

Sarkar, A., K. K. T. Goh, R. P. Singh, and H. Singh. 2009. Behaviour of an oil-in-water emulsion stabilized by $\beta$-lactoglobulin in an in vitro gastric model. Food Hydrocoll. 23:1563-1569.

Shimizu, M., H. Miyaji, and K. Yamauchi. 1982. Inhibition of lipolysis by milk-fat globule-membrane materials in model milk-fat emulsion. Agric. Biol. Chem. 46:795-799.

Shribak, M., J. LaFountain, D. Biggs, and S. Inoue. 2007. Quantitative orientation-independent differential interference contrast (DIC) microscopy coupled with orientation-independent polarization microscopy. Microsc. Microanal. 13:10-11.

Singh, H. 2006. The milk fat globule membrane-A biophysical system for food applications. Curr. Opin. Colloid Interface Sci. 11:154163.
Singh, H., A. Ye, and D. Horne. 2009. Structuring food emulsions in the gastrointestinal tract to modify lipid digestion. Prog. Lipid Res. 48:92-100.

US Pharmacopeia. 1995. Simulated intestinal fluid. In Official Monographs. US Pharmacopeia, Rockville, MD.

US Pharmacopeia. 2000. Simulated gastric fluid. Page 2235 in The National Formulary 19. Vol. 24. US Pharmacopeia Board of Trustees, Rockville, MD.

van Aken, G. A. 2010. Relating food emulsion structure and composition to the way it is processed in the gastrointestinal tract and physiological responses: What are the opportunities? Food Biophys. 5:258-283.

van Aken, G. A., E. Bomhof, F. D. Zoet, M. Verbeek, and A. Oosterveld. 2011. Differences in in vitro gastric behaviour between homogenized milk and emulsions stabilised by Tween 80 , whey protein, or whey protein and caseinate. Food Hydrocoll. 25:781-788.

Vanderghem, C., F. Francis, S. Danthine, C. Deroanne, M. Paquot, E. De Pauw, and C. Blecker. 2011. Study on the susceptibility of the bovine milk fat globule membrane proteins to enzymatic hydrolysis and organization of some of the proteins. Int. Dairy J. 21:312-318.

Verger, R. 1997. 'Interfacial activation' of lipases: Facts and artifacts. Trends Biotechnol. 15:32-38.

Ye, A., J. Cui, and H. Singh. 2010. Effect of the fat globule membrane on in vitro digestion of milk fat globules with pancreatic lipase. Int. Dairy J. 20:822-829.

Ye, A., J. Cui, and H. Singh. 2011. Proteolysis of milk fat globule membrane proteins during in vitro gastric digestion of milk. J. Dairy Sci. 94:2762-2770. 